\title{
Techniques for Producing Export-quality Tropical Horticultural Crops
}

\author{
Carl W. Campbell \\ University of Florida, Tropical Research and Education Center, \\ 18905 SW 280th Street, Homestead, FL 33031
}

\begin{abstract}
Tropical horticultural crops have been established in international trade for a long time. Banana and pineapple are good examples. Many crops, however, have been little-known outside the tropics until recently, when a growing interest in new and different fresh commodities in developed countries has stimulated increased export trade from the tropics. Many governments look upon this trade as a good way to earn foreign exchange and to increase employment in their countries.

Some tropical horticultural crops, particularly herbaceous species, have a tradition of production by relatively formalized procedures. With others, particularly tree crops, cultivation is less formal. These often are planted in gardens, pastures, parks, or roadside areas; some are harvested from the forest. Care of crops grown in this way is usually casual and the fruit is sold in local markets or consumed locally. It is difficult with crops such as these to convince growers that more formalized culture is necessary or economically justified. Improvement in care must be made, however, if horticultural crops of sufficiently high quality for export are to be produced.
\end{abstract}

\section{PRODUCTION INFORMATION}

Efficient production requires basic information on all aspects of growing the crop. For a few tropical horticultural crops, extensive information has been acquired through research. Examples include fruit crops such as avocado, banana, citrus, mango, papaya, and pineapple; vegetables such as cucumber, green beans, pepper, and tomato; floral crops such as anthurium, carnation, chrysanthemum, and rose; and various foliage plants.

For many crops, however, relatively little information on production is available; e.g., acerola, atemoya, breadfruit, carambola, guava, mamey sapote, passion fruit, soursop, winged bean, and chayote, among others. The information available is scattered through a variety of bulletins, books, and unpublished reports in many countries and is difficult to retrieve.

Fortunately, there is a strong trend now for governments and development agencies to support the compilation of research information bases as an early step in crop-oriented development projects. Information collected through literature searches is critically reviewed and organized into forms that can be used as guides to production. As searches are made, areas of information deficiency become apparent that serve as directions for future research.

Until recently, most agricultural information has been organized into conventional reports, bulletins, or circulars. This method still has value, but recently there has been an increasing trend to computerize agricultural databases. In Florida, for example, databases have been developed for such horticultural crops as avocado, lime, mango, snapbeans, strawberry, and tomato. Computerized databases have the great advantage that they can be updated easily with respect to information that changes frequently, such as pesticide recommendations. With the growing availability and use of computers throughout the world, these databases can be powerful tools in the dissemination of agricultural technology.

Simply accumulating information is not enough; it must be communicated effectively to producers through activities known as extension or technology transfer. Some countries or organizations have effective extension services, but most do not. The development and implementation of an effective extension mechanism is one of the basic components of a good development program. This need is generally understood and agreed upon by everyone involved, but often difficult to accomplish, usually for political reasons. Those who do the research are in a different governmental agency than the people who are supposed to disseminate the information. Resolution of this problem is a worthy goal.

\section{CROP SELECTION}

A critical step in horticultural crop development is the choice of crops to be emphasized. Success depends on selecting those that are reasonably well-adapted to the area and marketable. Adaptation testing is essential for any crop that is new to an area. To some extent, adaptation can be predicted from crop performance in similar regions, but there are too many variables involved to be certain of success without testing in specific locations. When it is determined which crops to grow, producers need to obtain good planting stock. This often requires initial introductions of seed or vegetative propagules from public or private sources in other countries. Introduction of plant materials from other countries should be controlled by a quarantine system adequate enough to prevent inadvertent introduction of pests or diseases.

Some crops can be propagated satisfactorily from seed. Many can only be propagated true-to-type by vegetative propagation. With many tropical crops, both seed and vegetative propagules are shortlived after removal from the plants on which they were produced. Improvements in packaging and transportation methods have helped greatly in long-distance transport of tropical plant material. Recent developments in tissue culture methods offer the possibility of tremendous improvement in propagation and dissemination of diseasefree propagules of tropical crops. Some species are already being propagated in this way. However, tissue culture methods remain to be developed for most woody species.

A desirable long-term goal of a plant introduction program is the 
establishment of broad germplasm bases for important crop plants. These are the source of genetic material for breeding and selection of new, locally adapted cultivars that can attain great importance in the crop production system of a country. Among fruit crops, avocado and mango are good examples of heterogeneous species that lend themselves well to local adaptation through selection of new cultivars.

\section{CULTURE}

\section{Nurseries}

Production of vegetatively propagated woody plants is so specialized that most growers prefer to buy their plants ready for field planting rather than to do their own propagation. Well-organized, efficient nurseries that follow strict sanitation procedures are required to produce clean, healthy plants. Many nursery plants are field-produced in the soil, but the current tendency is toward container production. Containers made of plastic, metal, or clay can be used, but inexpensive containers made of woven leaves have been used in some places. It is important to avoid leaving plants in containers for so long that they become rootbound, because such plants do not grow well when set out in the field.

Natural soil can be used in the containers if it is free of pests and diseases, but clean artificial media are often preferable. These can be made from materials such as sand, sawdust, wood chips, peatmoss, and other plant fibers, or manufactured materials such as vermiculite or perlite. Flood irrigation should be avoided in the nursery as it promotes the spread of diseases.

Appropriate methods of propagation that need to be taught to nursery workers include grafting, budding, layerage, rooting of cuttings, and division of vegetative plant parts. Optimum methods of propagation differ according to crop species, climate, and cultural methods that will be used.

\section{Soils and fertility}

Producers are likely to use their best soils and the most favorable topography available for planting of high-income crops. Many producers, however, have only relatively poor land available. Many growers need assistance with such techniques of land use and conservation as terracing, mulching, or planting of cover crops or perennial crops, etc.

Even with fertile soils, sustained crop production eventually necessitates the use of fertilizers to supply essential elements for continued production. Poorer soils, "of course, need regular fertilizer programs from the start for good production. Usually, it is possible to adapt existing technology to solving special problems that occur because of unavailability of certain nutrients. An example is the use of chelates of iron, zinc, and manganese to correct deficiencies in high-pH soils. These materials are expensive and maybe difficult to obtain, but their use often is economically justified because of dramatic increases in crop yield and quality.

Research and extension workers should encourage the use of locally available materials where possible to supply mineral elements and improve soil structure and nutrient-holding capacity by maintaining a favorable level of organic material. Chemical fertilizers that must be imported are usually difficult to obtain and expensive. Governmental agencies can assist producers by providing favorable import regulations and duties.

\section{Water}

Nearly all areas where crops are cultivated have some periods in which evapotranspiration exceeds rainfall and crop plants undergo moisture "stress. To avoid yield reduction and adverse effects on crop quality, some form of irrigation is necessary at these times. Irrigation methods exist for almost every situation, provided an adequate source of water exists. The bucket method, carrying containers of water by hand, is used in many places. Flood irrigation generally is the least expensive method and the most widely used. Drip and microsprinkler irrigation systems are increasing in importance in the tropics and are very effective. Growers usually find that the expense of irrigation is justified for high-income crops to produce economic yields of high quality.

In some places in the tropics, it is necessary at times to shelter horticultural crops from excessive rain to get good production. Most growers use local materials to build a framework and cover it with sheets of translucent plastic. Crops must produce a high return to justify the expense of this method, which is used primarily for vegetable and ornamental crops.

\section{Cropping systems}

Multiple cropping, defined as the production of two or more crops on the same piece of land in a year, is a common practice in the tropics. This may take the form of intercropping, in which two or more crops are grown simultaneously, or sequential cropping, in which two or more crops are grown in sequence during the year. Hundreds of combinations of crop species and sequences can be made and growers can get great productivity from good land.

Multiple cropping promotes diversification and allows the grower flexibility in adjusting to short- and long-term changes in the production and marketing situation. This system lends-itself well to good land management and conservation on steep terrain. Intercropping has the potentially important disadvantage of being difficult to adapt to mechanized cultural operations, which creates problems, especially for large-scale agricultural operations.

An interesting aspect of multiple cropping is the development of extensive "agroforestry" projects in which horticultural crops, especially tree crops, are grown in combination with trees producing firewood, lumber, and other forest products. In many areas with poor soils and rough terrain, such systems may offer the best possibilities for profitable agriculture because more intensive crop cultivation is not feasible.

\section{Timing of production}

The economic success of production for export depends not only on the quality of the produce, but on the ability to market it for a profit. This depends on getting the crop to its destination at a time when there is minimal competition from other sources. Thus, much emphasis is placed on the search for "windows" when the crop is scarce in the target country. Producers in the tropics have some advantages in this respect because planting is possible at most times of the year. Plantings of short-term crops, such as vegetables and ornamental, can be adjusted to produce a harvest at the most favorable time.

Even where the time of crop maturity is strongly controlled by climatic cycles and therefore highly seasonal, differences in latitude allow for much variation in time of harvest. A good example is the mango, which can reach U.S. markets from Brazil in December and January and from Haiti in March and April, when there are few local fruits available.

Another strategy is to manipulate the production cycle in some artificial ways. The pineapple plant can be forced with certain growthregulating chemicals to flower at will, provided the plant is large enough. This allows growers in the tropics to produce fruit in serial plantings at any time of the year. Research is in progress with the objective of controlling the time of flowering and fruit production in other crops. Examples are work with flowering of 'Tahiti' lime in Florida and with flowering and fruit set of acerola in Barbados.

\section{Plant protection}

Pests, diseases, and weeds greatly affect crop yield and quality, and their management is a major expense in the production of many crops. Non-chemical control methods are desirable wherever they are effective enough to maintain profitable yields and good crop quality. Good management practices can prevent or reduce the development of harmful organisms. Cultivars resistant to pests and diseases are available for many crops. Parasitic or predatory organisms can be used in biological control programs.

In many cases, however, chemical pesticides still are the only known way to achieve economic control of pests, diseases, and weeds. Growers producing crops for export must apply pesticides at dosages sufficient to control pests, but not so high as to leave 
residues that exceed the tolerances of importing countries. The absence of pesticide registration for many minor tropical crops severely limits chemical pest management procedures.

A concept of plant protection that is of great interest to many countries is the establishment of production zones free of pests and diseases. Through careful inspection or eradication programs, production zones can be declared free of designated pests or diseases. Crops produced there can then be shipped to other countries without pesticide treatment. The success of this concept depends on thorough initial inspections, followed by continuous, conscientious monitoring to assure that the area remains pest-free. Success also depends on political agreements between participating nations, which can be difficult to achieve and maintain.

\section{CONCLUSION}

Successful crop production systems are complicated and require good management by growers. To produce crops successfully for the international export trade, it is essential to decide which crops to emphasize and. then establish information bases for each one through literature searches and experimentation. Then, technology transfer or extension mechanisms must be established through which the necessary information is conveyed to those who will grow and handle the crops. Extension activities require capable people who have the necessary organizational and logistic support to do an effective job.

Crop production is only apart of a successful process of international crop exportation, but it is an important part. Efficient crop production is well worth the attention of governments of developing countries as means of improving their economies and the welfare of their people.

\section{References}

Brathwaite, C. W. D., R. Marte, and E. Porsche. 1986. Pests and diseases as constraints in the production and marketing of fruits in the Caribbean. Intcramer. Inst. for Coop. on Agr. Port of Spain, Trinidad and Tobago.

Casseres, E. 1980. Producción de hortalizas. Inst. Interamer. de Cienc. Agr. San Jose, Costa Rica.

Martin, F.W. 1984. Handbook of tropical food crops. CRC Press, Boca Raton, Fla.

Martin, F. W., C.W. Campbell, and R.M. Ruberte. 1987. Perennial edible fruits of the tropics; an inventory. USDA Agr. Hdbk. 642.

Purseglove, J.W. 1974. Tropical crops. Dicotyledons, vols. land 2. Longman, London.

Purseglove, J.W. 1975. Tropical crops, Monocotyledons, vols. 1 and 2. Longman, London.

Samson, J.A. 1986. Tropical fruits, 2nd cd. Longman, London.

U.S. Dept. of Agr. 1984. Agricultural marketing handbook for Caribbean Basin products. Office of Intl. Coop. and Dev., USDA, Miami, Fla.

\title{
Transportation
}

\author{
James Soule \\ Department of Fruit Crops, University of Florida, Gainesville, FL 32611
}

This paper deals with transportation as it relates to the production, postharvest handling, and marketing systems within the food chain. It is, at times, the most important missing ingredient in the Caribbean Basin Initiative- (CBI) favored nations program.

One of the main problems confronting us today within the CBI program is a tendency to assume that concepts embodied in successful projects in one country can be transferred without alteration to similar projects in other countries. Each country, actually each enterprise and area, has important differences in cultural and other practices. Much of this has come about as participating countries, and the lending and donor institutions to which they turn, seek to find rapid solutions for their troubled economies. Unfortunately, much of the effort thus far has been directed toward the production aspects of developing new enterprises, while ignoring the other elements of the food supply system that are more important than production capabilities. Specifically, these are proper capitalization, technology, management, postharvest handling systems, and transportation.

Rather than designing projects that fit specific conditions for each of the CBI-favored countries, the parties involved attempt to mold the conditions to the general pattern and to ignore actual conditions in the real world. It is just not working. For example, there are countries attempting to produce vegetables for winter North American markets that have absolutely no business being in those markets, not from the standpoint that they lack adequate land, water, or microenvironmental conditions to produce the crops. The real problem is that, once produced, there is currently no feasible way that they can deliver their merchandise to the markets in a timely, consistent, high-quality, cost-effective manner. The missing key element in their food production and marketing system is transportation. The CBI region is strewn with the relics of projects that serve as testamentary monuments to the failure to recognize that the

Permission was given by James R. Rinella, President, Sun World, Indio, CA 92201 to adapt his speech, presented at the 84th ASHS Annual Meeting in Orlando, Fla., for publication as a colloquium paper.

'ASHS Associate Editor for Colloquia and Features. proper links in the food production and marketing systems were not in place to assure viability of the projects from the outset of such endeavors.

The approach here is not to enumerate the numerous problems that exist, but rather to attempt to persuade the growers and shippers to put pressure on agencies such as the World Bank, USAID, and others to commit resources toward the development of dedicated transportation networks to service the CBI regions that we are interested in seeing succeed. The commercial private transportation sector, made up of the many shipping lines that now ply back and forth among Central America, the Caribbean, Gulf of Mexico, and eastern seaboard ports of the United States, is doing a relatively good job considering the present state of development in the CBI region. The scope of the projects under development, their geographic dispersement, seasonal compression of their demand requirements, vessel sizes and configurations, and frequency of port call scheduling on a country-by-country basis are such that they do not provide for the proper harvest, packing, and shipping requirements. Most fresh fruit and vegetable operations require that export quality volumes are optimized and able to be transported in a timely manner for delivery to the targeted market centers.

Frequently, an exporting country may have one container ship calling each week, while others sometimes have two or three vessels within a week, with a period of 10 to 14 days ensuing before the next visit. It is often difficult to hold fruit and vegetables in the field or to stagger harvests or locations until the next ship is in port and still obtain maximum yields, maintain market-quality size, configuration, quality standards, etc., given the perishable nature of the product. The upshot is that the product may be harvested too early or too late, or it rots in the field, especially if cold storage facilities are not available so as to accumulate sufficient volume for the arrival of vessels later.

At the same time, most of the countries are still predominantly net importers, as their self-sufficiency and potential export projects are still in developmental stages. This means there is more traffic outward- (south) bound from the United States than there is inward (north) from these same countries. This direction of traffic is com- 